\title{
Intelligent Technologies in the Oil and Gas Industry
}

\author{
Sergey Milyushenko ${ }^{1}$ \\ ${ }^{1}$ Siberian State Automobile and Highway University, 6440805 Mira av., Omsk, Russia
}

\begin{abstract}
The article is devoted to the discussion of improving the quality of oil and gas production, through the introduction of new technologies for the extraction and processing of natural resources. As well as to the procedure, which aims to ensure the increase in the volume of mineral resource (liquid hydrocarbons) and to optimization of production costs in modern enterprises of oil and gas industry. The development of "smart" technologies in the oil and gas industry is mainly associated with a reduction in proven oil and gas resources in the Russian Federation. However, there are oil and gas reserves in places with an unfavorable climate, which significantly increases the cost of developing such deposits. For solving this problem, the "smart" technology "Smart Field" development is proposed.
\end{abstract}

\section{Introduction}

Smart Field is a set of software and hardware tools that allows managing an oil reservoir to increase hydrocarbon production. Such a system allows to carefully exploit the oil field, as well as significantly increase its service life. The economic effect of the introduction of this technology is to reduce the cost of electricity, which is spent on deposits and reduce the burden on the environment in this place.

The "intellectual field" is based on the concept of intellectual management, such management methods use different approaches of artificial intelligence, namely, evolutionary computing, artificial neural networks, machine learning, genetic algorithms, etc.

\section{Materials and Methods}

The main advantage of modern technology is the automation of cyclic processes, which significantly reduces the human factor in decision making. The use of this technology will reduce the risk of various abnormal situations in the process of operating the oil rig and allows monitoring the process remotely in real time.

How this system identification works. It always has three main components: a reader (input), an identifier (card, tag, key fob, tag) and a computer data processing system (PC). The reader emits electromagnetic energy into the surrounding space, it is received by an 
identifier. The signal from the reader generates a response signal, which is then received by the reader's antenna, processed by its electronic unit and sent via interface to the PC (Fig. $1)$.

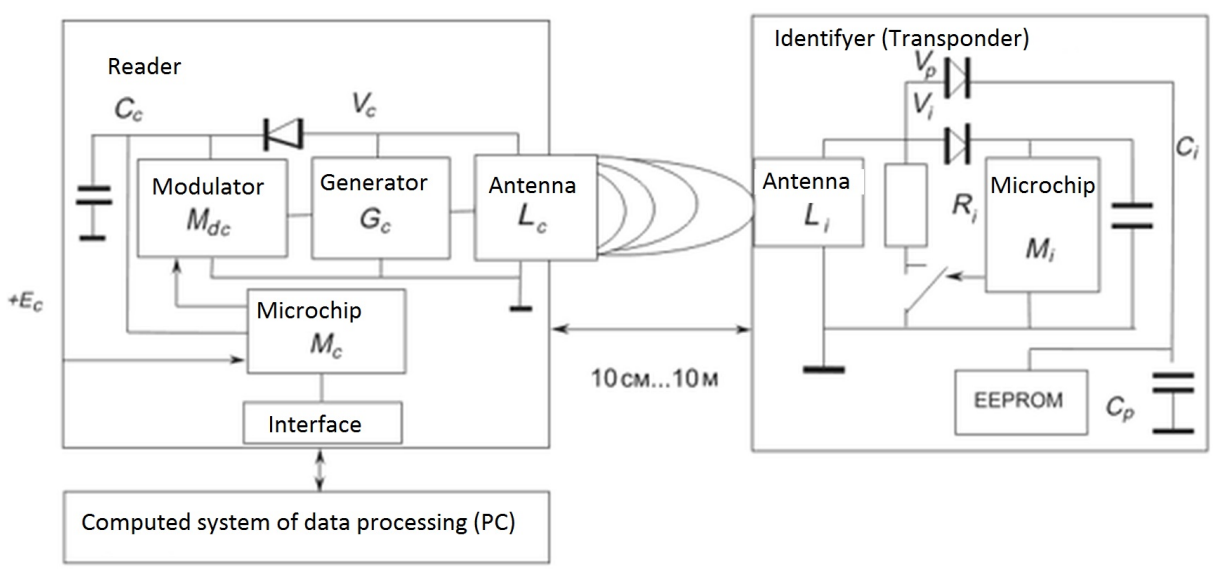

Fig. 1. The principle of operation of the RFID system

The principle of object identification: The RFID tag is a chip that stores the tag's identification number, and also has the ability to transfer data to the reader through a special device (antenna). In the event that such a label falls within the range of the reader, the following reader will record the moment of transfer of the data contained on the tag, read the necessary information and transmit it to the accounting system using the server. The accounting system makes an analysis of the data obtained by a given algorithm (Fig. 2).

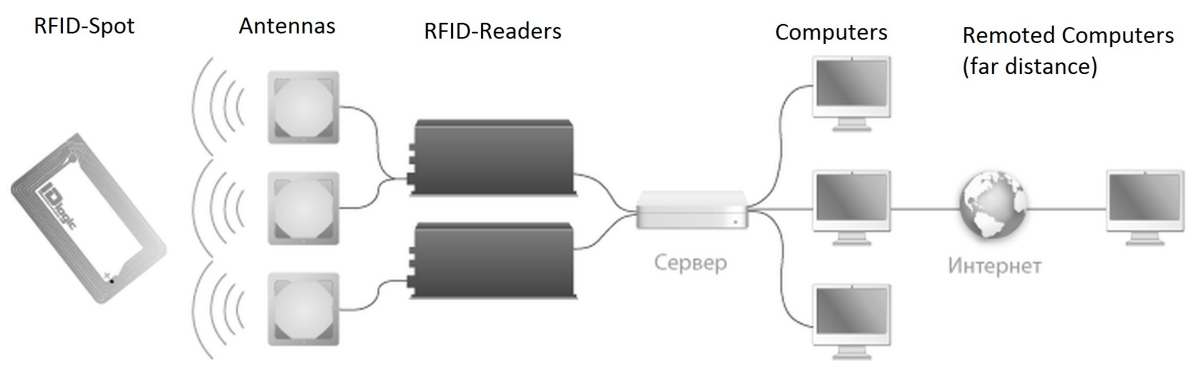

Fig. 2. The principle of operation of RFID automatic identification of objects.

According to the signal recognition distance between the tag and the reader, there are three types of systems: long-range identification (from 5 to 300 meters), medium identification (from 20 centimeters to 5 meters), short-range identification systems (up to 20 centimeters). [1]

RFID technologies in the modern world are very common. Thus, in automobile sports, most racing cars are equipped with Identec Solutions sensors that transmit an identification number every 0.5 seconds, which makes it possible to fully automate stations to collect and display the level of sound intensity. [2] Such software in turn allows monitoring remotely in real time. Also, this system is used in retail. The technology allows non-contact identification of various objects. It is enough to hold the RFID terminal of data collection 
near the subject and all information about the product will automatically be transferred to the database of the relevant organization. RFID technology makes it possible to conduct an inventory without human intervention, which significantly reduces time and financial costs.

This technology is also developing in the oil and gas industry [3-7]. The technology is a method of automatic identification of objects in which data is read or written by means of radio signals. Any system that involves the use of this technology includes a reader (input organizer or interrogator) and a transponder (also known as an RFID tag, the term RFID spot is also used).

Such software can be used not only in the oil and gas extracting but in processing too. One of the representatives of this technology is Go-RFID software and hardware. It is widely used in large gas and oil fields in Russia and can monitor the state of drilling equipment, the frequency of their servicing, its movement, and in case of drilling equipment going out of operation, it offers affordable analogues.

Thanks to these technologies, the company is able to optimize the production process, reduce consumption of electricity, water, steam and other energy resources, which has a positive effect on the cost of production of oil or gas. It can also should be noted that the entire process control takes place remotely, which saves on labor and increases the extraction of oil and gas resources, which will lead to a profit increase.

\section{Results and Discussion}

The development of hydrocarbon deposits of the oceans today is reaching a new level of exploitation. Russian oil and gas companies in the development of offshore and deepwater fields should use the latest achievements of innovative technologies for the exploiting of oil and gas fields in real time (Fig. 3).

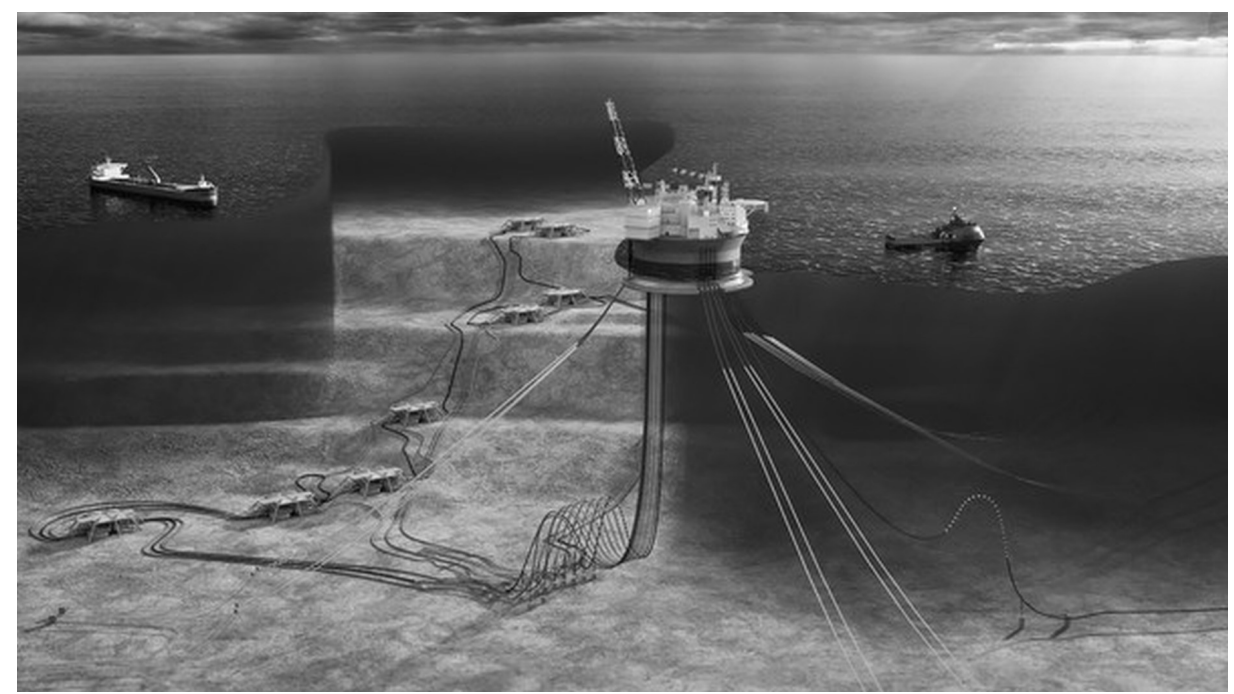

Fig. 3 Underwater mining complexes.

The idea of using an intellectual field is to manage objects of the oil and gas industry remotely, which will significantly increase the energy efficiency of equipment operation, as well as a more efficient model of personnel management. Work on the basis of an intellectual field will increase the production of hydrocarbon raw materials and will lead to 
a reduction in risks. In the future, it is planned to operate such installations without human participation; all the management will be carried out remotely from anywhere in the world.

First it is necessary to conduct automation in the area of exploration and production, the solution of the problem is not possible without a digital model of the landscape of the field. 3D / 4D geomechanical and physico-and-chemical modeling allows you to make a forecast about the presence of hydrocarbons and determine the oil and gas presence, without using an expensive geological method (Fig.4). In this case, there is no need for geologists to go to the place where exploration of deposits will be carried out using various traditional methods, the use of digital models will significantly reduce the costs of exploring new deposits.

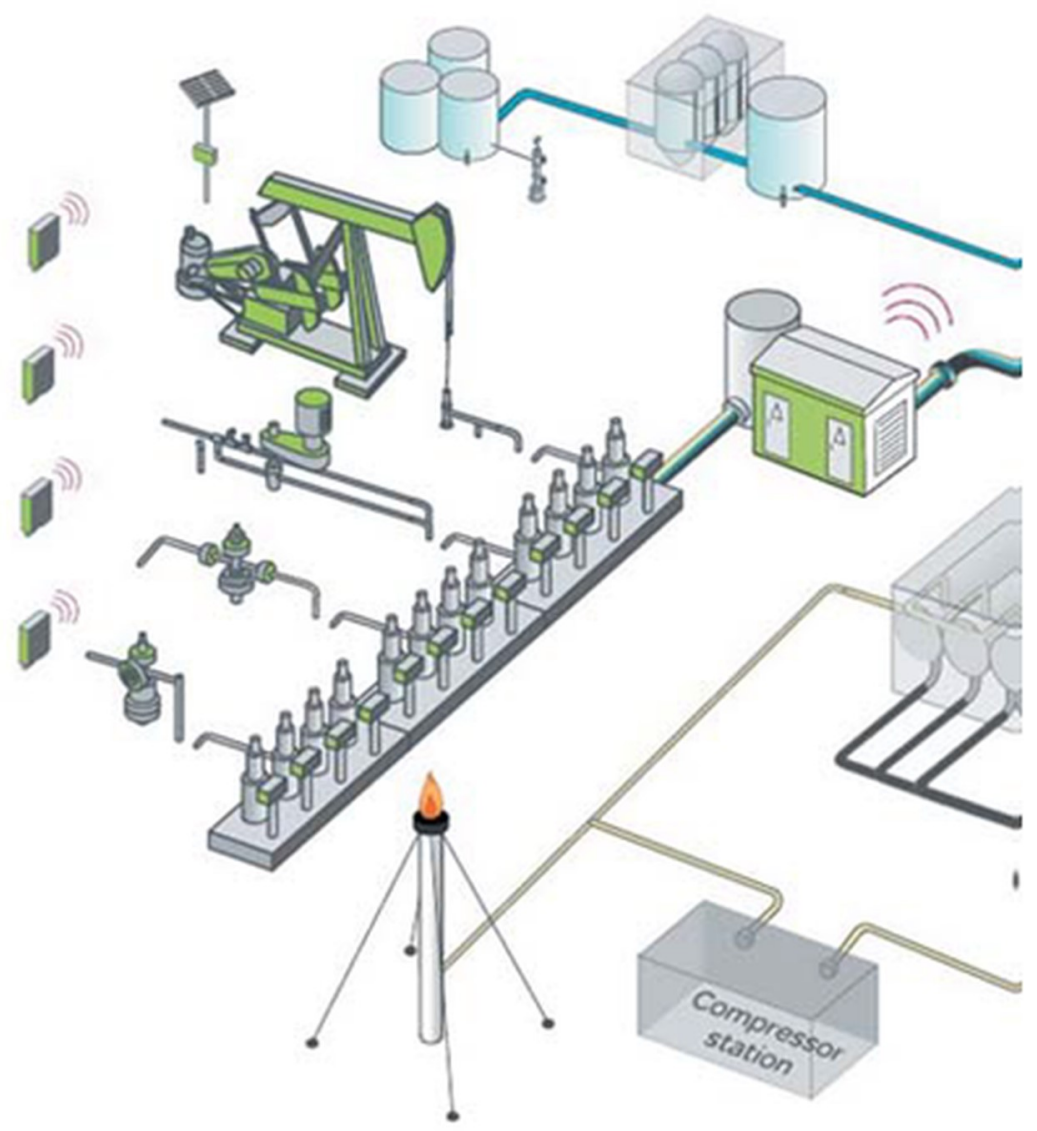

Fig.4. Diagram of interaction of control systems in the digital environment.

Most of the deposits, which are located on the territory of the Russian Federation, are exploited using the bush method. The wells are located at a short distance from each other, as close as it is possible. Sometimes wells can be located at a considerable distance from each other. Therefore, the installation of a communication cable for considerable distances from the control room is practically impossible. In this case, the methods of the telemechanic system using controllers and radio modems are used.

To accomplish this task of intellectualization, a control cabinet is installed at the facility. Information generated during the process of technological equipment work is 
controlled with its help. Then, the received information is transmitted via radio modem to the control tower. The use of such a method is possible for local control in a limited space. If the automation on the cluster plants is not fully available to monitor the state of the bush operation, then more complete information is needed.

To solve this problem, the controller for wired sensors are needed. In this case, it is necessary to pull the communication tires to each cluster installation, which significantly increases the cost of installing such a system. There are wireless analogs of "wired" sensors. In this case, it is not necessary to stretch the cables for each cluster installation as a whole throughout the facility. As a result, it ensures avoiding significant financial costs, subject to significant remoteness of cluster plants from each other. In this case, the time required for installation of the relevant equipment necessary for the automation of the facility is significantly reduced.

In this case, such wireless solutions can be combined with any system, which allows them to be integrated into the existing industrial management system. The possibility of remote monitoring and exploitation of intellectual fields led to a $20 \%$ reduction in time to the wells and from the wells, and inspired conservation of some gas compressors due to higher production and less burning of petroleum products.

\section{Conclusion}

The use of modern wireless technologies allows you to receive information from local control points to the central control room. All information obtained with this object is analyzed, and on its basis conclusions about the operation of the installations are drawn. Based on this, workers can change the settings of the plant operation.

Intellectual fields are being actively introduced into the oil and gas industry of the Russian Federation. The training methods of such systems (neural networks) are applied at all stages of field development. Such networks process large amounts of data that are used to explore new deposits. They also apply their adaptive control algorithms for complex field installations.

The intelligence of the systems is that it allows adjusting each parameter depending on disturbing factors (quality of raw materials, external factors, temperature modes of operation) beforehand calculating and taking into account various scenarios of behavior.

Intellectual systems can carry out tuning of PID-regulators, on the basis of the obtained data, which will significantly increase the performance of the plant as a whole. Such methods will improve the efficiency of operations performed, optimize staff performance, which will lead to lower costs and better productivity of the installation. In the case of using the intelligent systems in the oil and gas industry, the costs of technological operations will be reduced, and the volume of production will increase due to expanding the productivity of equipment and personnel.

The trend of the development of the oil and gas sector in the global economy is the intellectualization of gas and oil deposits. The use of intellectual field technology can encourage oil and gas companies to use new and existing fields to the maximum, optimize the load of the wells, reduce production costs and increase profitability.

\section{References}

1. S. Zlatoustovsky, RFID tracks the noise level on the German high-speed race tracks. URL: https://www.rfidexpert.ru/ru/story/878 (accessed 20.03.2019).

2. Blog about positioning, data transfer, voice communication and the Internet of things. URL:https://realtrac.com/ru/company/blog/ (accessed 20.03.2019). 
3. Offshore drilling rigs on the Norwegian shelf. URL: https://pikabu.ru/story/morskie_burovyie_ustanovki_na_norvezhskom_shelfe_5175995 (accessed 20.03.2019).

4. Innovative technologies for the development of oil fields in real time. URL: http://oilgasjournal.ru/vol_7/eremin.pdf (accessed 20.03.2019).

5. Gazprom Oil in 2017. Strategic report (Gazprom, Moscow, 2018)

6. Order of the Government of the Russian Federation of November 13, 2009 No. 1715-p "On the Energy Strategy of Russia for the Period up to 2030" (Russian Newspaper, Moscow, 2009)

7. Strategy for the development of the Arctic zone of the Russian Federation and ensuring national security for the period up to 2020 (approved by the President of the Russian Federation on February 13, 2013) (Russian Newspaper, Moscow, 2009) 